\title{
The telosome/shelterin complex and its functions
} Huawei Xin*, Dan Liu** and Zhou Songyang*

\begin{abstract}
Addresses: *Verna and Marrs McLean Department of Biochemistry and Molecular Biology, Baylor College of Medicine, Baylor Plaza, Houston, TX 77030, USA. ${ }^{+}$Cell-Based Assay Screening Service Core, Baylor College of Medicine, Houston, TX 77030, USA.
\end{abstract}

Correspondence: Zhou Songyang. Email: songyang@bcm.edu

Published: 18 September 2008

Genome Biology 2008, 9:232 (doi:I0.I I86/gb-2008-9-9-232)

The electronic version of this article is the complete one and can be found online at http://genomebiology.com/2008/9/9/232

(c) 2008 BioMed Central Ltd

\begin{abstract}
The telomeres that cap the ends of eukaryotic chromosomes serve a dual role in protecting the chromosome ends and in intracellular signaling for regulating cell proliferation. A complex of six telomere-associated proteins has been identified - the telosome or shelterin complex - that is crucial for both the maintenance of telomere structure and its signaling functions.
\end{abstract}

Telomeres are specialized structures at the ends of eukaryotic chromosomes that help to maintain genome integrity in eukaryotes by preventing chromosomal rearrangements or chromosomes fusing to each other, and by enabling complete replication of the ends of the linear DNA molecules. Telomeric DNA is composed of a series of sequence repeats and terminates in a 3' single-stranded (ss) DNA overhang. At each round of DNA replication the telomeric DNA becomes shorter, but it can be regenerated by the enzyme telomerase, an RNA-containing DNA polymerase. Both the double and single-stranded telomeric DNA is bound and protected by DNA-binding proteins that in turn associate with other signaling proteins/complexes to achieve telomere-end protection and length control. The length of telomeric DNA is maintained by the enzyme telomerase, but in addition, six telomere-associated proteins - TRF1, TRF2, POT1, RAP1, TIN2 and TPP1 in mammalian cells - have been shown to form a complex known as the telosome, or shelterin complex, that is essential for telomere function [1-10]. Here we will briefly review the composition of the telosome, its role in telomere maintenance, and its connections with intracellular signaling pathways.

Telomere repeat factor-1 (TRF1) and - 2 (TRF2) are related proteins that share a number of sequence and organizational similarities, and along with protection of telomeres-1 (POT1), they interact directly with telomeric DNA. RAP1 (the human homolog of the yeast telomeric protein Rap1), TRF1interacting protein 2 (TIN2), and TPP1 (also known as
TINT1/PTOP/PIP1) associate with these DNA-binding proteins to form the core telosome (Figure 1). Various signaling pathways originate from these core telomeric proteins and their subcomplexes, and from this it has been possible to deduce a telomere 'interactome' [11]. In this interactome, the telosome serves as the core building block, coordinating protein-protein interactions and protein complex cross-talk on the telomeres.

\section{TRFI and TRF2 and their interaction networks}

TRF1 and TRF2 each bind telomeric double stranded (ds) DNA as homodimers, with dimerization mediated by the TRF-homology (TRFH) domain [3,4,12]. TRF1 homodimers are postulated to monitor telomere length, whereas TRF2 homodimers serve to stabilize telomeric loop (t-loop) formation and protect the telomere end ( $\mathrm{t}$-loops are structures that appear to form as a result of the 3' overhang invading the duplex telomeric repeats). TRF1 and TRF2 interactions with a number of proteins within the interactome have also been mapped to their respective TRFH domains [13]. TRF1 has a propensity for binding long tracts of dsDNA whereas TRF2 binds the ds/ssDNA junction [14]. Both TRF1 and TRF2 have carboxy-terminal Myb domains, which are essential for binding directly to telomere duplex DNA $[3,4]$.

Human TRF1 and TRF2 differ from each other at their amino terminus, which comprises an acidic region in TRF1 and a basic region in TRF2. The function of these regions is 


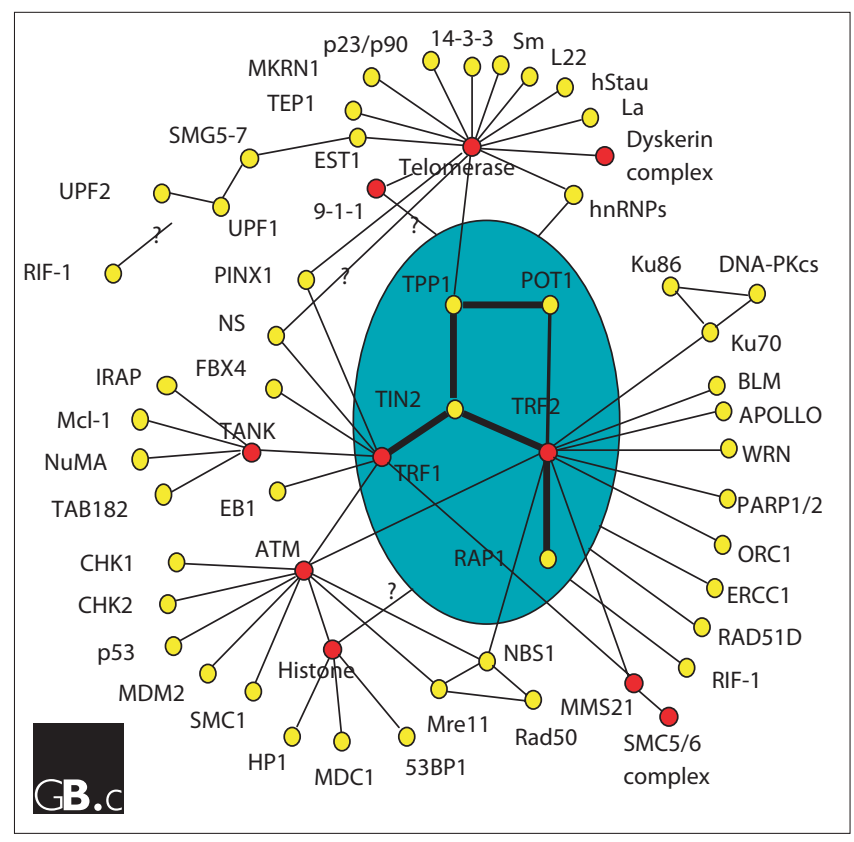

Figure I

The telomere interactome. This diagram depicts most of the known protein-protein interactions centered on telomeric proteins. The telosome is shaded in blue. Lines indicate protein-protein interactions, yellow dots indicate nodes and red dots indicate protein hubs.

poorly understood, although recent studies suggest that the basic amino-terminal domain of TRF2 is important for binding of the ds/ssDNA junction and for the supercoiling of telomeric DNA, and may regulate the formation and stabilization of the t-loop structure [15-17]. Deletion of the basic region of TRF2 does not affect its targeting or binding to telomeres in vivo; the overexpression of this truncated protein does, however, lead to disruption of telomere end protection and the induction of cellular senescence and apoptosis $[18,19]$. Overexpression of a TRF2 construct lacking both the basic and the Myb domains leads to an increased occurrence of chromosomal fusions and interchromosomal bridging [20].

As illustrated in Figure 1, TRF1 and TRF2 also function as protein-interaction hubs within the telomere signaling network, interacting directly with the other members of the telosome and with a diverse array of proteins and protein complexes that are involved in the cell cycle and in DNA repair and recombination, to maintain telomere structure and length [2,21-28]. TRF1 has been postulated to modulate the length of telomere repeats primarily via its interaction with the telosome proteins TIN2, TPP1 and POT1, and with PINX1, an inhibitor of telomerase [7,9,10, 29-37]. For example, the direct interaction of TRF1 with PINX1 provides a possible mechanism for how TRF1 could regulate telomere length [34]. PINX1 may be recruited to the telomeres through its interaction with TRF1 and negatively regulate telomere length by directly inhibiting telomerase.
TIN2 was identified on the basis of its ability to interact with TRF1 in yeast two-hybrid assays [30]. TIN2 is a key component of the telosome, and associates with both TRF1 and TRF2 $[1,38,39]$. TRF1-TIN2 interaction occurs through the TRFH domain and the TIN2 carboxy-terminal domain $[13,30]$. TIN2 is a negative regulator of telomere length and is essential for bringing together the DNA-binding proteins within the telosome complex.

TPP1 interacts with both TIN2 and POT1, and is the link that connects the activities of the dsDNA-binding TRF1 to those of the ssDNA-binding POT1 [8-10]. POT1 binds ssDNA, regulates telomere length, and helps to stabilize the T-loop and protect the telomere end. TIN2 is the major TRF1-interacting protein, and TPP1 is the major POT1-interacting protein, so TPP1 links these two DNA-binding activities assembled on the telomeres. The TRF1-TIN2-TPP1-POT1 association illustrates an important path through which signals are communicated along a telomere. The functions of POT1 and TPP1 are discussed in more detail later.

In addition to the interactions described above, TRF1 can associate with tankyrase, a protein with poly(ADP-ribose) polymerase activity [33], end-binding protein 1 (EB1) [40], the nucleolar protein nucleostemin [41], and the F-box protein $\mathrm{FBX}_{4}$, which participates in protein ubiquitination [42] (Figure 1). Human EB1 is able to interact with and target the tumor suppressor protein adenomatous polyposis coli (APC) to microtubules in a cell-cycle-dependent manner. Tankyrase has been implicated in the control of spindle structure [43] and sister-chromatid cohesion [44], and thus through interactions with tankyrase and EB1, TRF1 could be involved in cell-cycle dependent regulation of telomere function. Levels of TRF1 protein can be controlled by tankyrase, FBX4 and nucleostemin $[41,42,45]$. TRF1 can be polyADP ribosylated by tankyrases [33], which may lead to its ubiquitination and subsequent degradation [45], while FBX4 is an E3 ligase specific for TRF1 ubiquitination via the Cul1containing SCF complex [42], which leads to proteasomal TRF1 degradation. Nucleostemin enhances TRF1 degradation by a ubiquitination-independent pathway [41].

Both TRF1 and TRF2 can be sumoylated by the SUMO ligase MMS21, a component of the SMC5/6 complex, which is involved in DNA repair and recombination [46]. A number of human tumors and tumor cell lines have a telomeraseindependent mechanism for telomere elongation that involves homologous recombination, and which is referred to as 'alternative lengthening of telomeres' (ALT) [47]. As demonstrated in cells that display ALT, sumoylation of TRF1 and TRF2 helps to promote the recruitment of telomeres to intranuclear macromolecular complexes called APBs (the equivalent of PML bodies in other cells) and promote telomere lengthening through homologous recombination. However, it remains to be determined whether TRF1 and TRF2 are similarly modified in other cell types. 
TRFI and TRF2 and DNA damage response pathways Both TRF1 and TRF2 are intimately linked with DNA damage response pathways. The ss/dsDNA structure at the telomere could be perceived by the cell as DNA damage, and TRF1 and TRF2 appear to be part of the mechanism that prevents a damage response being generated. TRF1 co-immunoprecipitates with the protein kinase ATM (ataxia telangiectasia mutated), a sensor of DNA damage, and can be phosphorylated by ATM both in vivo and in vitro $[48,49]$. Phosphorylation of TRF1 by ATM leads to impairment of TRF1's capacity to interact with DNA [49], and the expression of phosphorylation-site mutant TRF1 induces mitotic entry and apoptosis [40]. The MRN complex, functioning together with ATM, is also important for regulating TRF1 activity [49]. The MRN complex appears to be required for ATM-mediated phosphorylation of TRF1.

Numerous studies have demonstrated the essential role of TRF2 in telomere end protection. In addition to ATM, TRF2 also recruits a variety of other DNA damage-sensing and DNA repair proteins to the telomere, such as nucleases ERCC1/XPF [50] and Apollo [51,52]; the DNA repair MRN complex [53,54]; the helicases BLM [55] and WRN [55]; $\mathrm{Ku} 7 \mathrm{O} / \mathrm{Ku} 86[54,56]$, and poly-ADP ribose polymerases PARP1/2 [54,57,58] (Figure 1). The recruitment of these proteins presumably functions to prevent telomere ends being recognized as DNA breaks or to sensitize the cell to damage to the telomeres. It is equally possible that TRF2associated complexes of 'damage proteins' are different in composition or modification state from the canonical complexes involved in repairing radiation-induced doublestrand DNA breaks, given that the TRF2-based complexes normally do not evoke a cell-cycle checkpoint response $[59,60]$. It should be noted that TRF2 has been shown to localize to sites of high-energy radiation-induced DNA damage outside the telomeres [61,62]. Therefore, the association of TRF2 with DNA damage response proteins may have a role beyond telomere protection.

TRF2 mediates its protective function partly through heterodimerization with the telosome component RAP1, which contains a Myb domain [6]. In human cells, inhibition of RAP1 or dominant-negative expression of RAP1 truncation mutants led to elongated telomeres and loss of telomere heterogeneity [54,63]. TRF2 has also recently been shown to associate with the origin replication protein ORC1 [64], which implicates the origin recognition complex (ORC) in facilitating telomere replication. Despite the critical role of the ORC complex in eukaryotic DNA replication, how it is recruited to origins of replication is poorly understood. Sequence-specific DNA-binding proteins or epigenetic factors may play a role. In this case, the specific interaction between TRF2 and subunits of the ORC complex point to a possible mechanism for targeting the ORC complex to the telomeres. However, whether TRF2 does have a role in telomere replication remains to be determined.

Recent studies suggest that the TRFH domains are the first modular domains identified in telomere proteins that can recognize linear peptide sequences [13]. And those findings have further solidified TRF1 and TRF2 as the major hubs within the telomere interactome. The TRFH domains of TRF1 and TRF2 display distinct specificities and affinities for their targets, suggesting a new avenue of research for probing the function of TRF1 and TRF2, and deciphering how players from diverse pathways are recruited to the telomeres.

\section{POTI and TPPI and their functions}

While the telosome forms a platform to which additional players can be recruited (Figure 1), complicated interactions are also at play within the protein complex itself [11]. TIN2 and TPP1 are critical to its assembly [65], and the ssDNAbinding protein POT1 serves as the effector of the complex in its role of maintaining telomere integrity. Both POT1 and TPP1 contain one or more oligonucleotide/oligosaccharidebinding folds (OB folds) [66-70]. Recent work has highlighted the evolutionary conservation in both structure and function among OB-fold-containing proteins participating in telomere maintenance and integrity, such as POT1 and TPP1, compared with those involved in DNA protection, such as the heterotrimeric replication protein $\mathrm{A}$ (RPA) complex [66,67,71-77].

Genetic studies in yeast, Tetrahymena, plants, humans and mice support an essential role for POT1 in maintaining telomere integrity [7,78-82]. Unlike humans, mice contain two isoforms of POT1 - POT1a and POT1b [79,80]. Recent work has shown the functional dichotomy of these two isoforms, and provided much-needed insight into the evolutionary divergence and conservation of POT1 homologs in different species [78-80,83]. Conditional knockout studies of POT1a and POT1b suggest that both are needed for complete protection and maintenance of the telomeres $[79,80,83]$. While the two proteins have overlapping functions and each may compensate to some extent for the loss of the other, they are not interchangeable. In particular, POT1a is essential for suppressing DNA damage responses at telomere termini, whereas POT1b regulates the 3' ssDNA overhangs $[79,80,83]$. When the ends of chromosomes are not coated and protected by proteins, the telomeres (with or without the overhang) may be recognized as DNA damage, eliciting DNA damage response pathways. POT1b appears important for protecting the 3' overhangs from degrading nucleases. This functional difference may be achieved, in part, through the interaction of POT1a and POT1b with different sets of proteins in the telomere interactome. For example, one potential target of POT1b could be nuclease(s) that are involved in processing the 3' overhang [79]. 
Although both TRF2 and POT1 bind telomere DNA and are required for telomere capping, recent studies indicate that they regulate distinct signaling pathways $[84,85]$. Loss of function of TRF2 in a number of mammalian cell types (tumor and primary cell lines), and in cells from conditional TRF2-knockout mice, elicits DNA damage responses mediated mainly through the ATM pathway, whereas POT1 knockout triggers the DNA damage response pathway initiated by the protein kinase ATR (ataxia telangiectasia related) [84]. These results are consistent with the telomere interactome map (Figure 1), where TRF2 interacts with the MRN complex and DNA-PK, proteins that mediate repair of double-strand breaks, with which ATM is preferentially associated $[53,54,56,86]$. In addition, the repression of ATR activity by POT1 is probably a result of POT1 binding telomere ssDNA and inhibiting ATR activation by blocking access of the single-strand binding protein RPA, by which ATR is recruited, to the telomere [84,87]. As shown in the interactome map, few proteins are known to bind directly to POT1. How POT1 signals through pathways other than the ATR pathway merits further investigation.

In the cilate Oxytricha nova, heterodimers of the OB-fold telomere end-binding proteins TEBP- $\alpha$ and TEBP- $\beta$ are bound to the TTTTGGGG repeats of telomeric DNA. TEBP$\alpha$ contains three OB folds, two of which are involved in SSDNA recognition while the third interacts with TEBP- $\beta$ [68]. Human POT1 is a homolog of ciliate TEBP- $\alpha$. Although TPP1 lacks an obvious OB fold, careful biochemical, structural and molecular studies have revealed that it does indeed contain an OB-fold structure, and that it is a functional homolog of the ciliate TEBP- $\beta[66,67]$. Whereas TPP1 exhibits little or no telomere ssDNA-binding activities in gel-shift experiments, a POT1-TPP1-DNA ternary complex can form in these assays. TPP1 has also been shown to enhance POT1 DNA-binding activity [66,67], supporting the model that POT1 may interact with DNA in the form of a heterodimer with TPP1. The TPP1-POT1 heterodimer has been postulated to modulate telomerase access to the telomeres.

In ciliates, TEBP- $\beta$ can also promote G-quadruplex formation [88]. G-quadruplexes are tetrads of hydrogen-bonded guanine bases that can form in G-rich DNA and RNA sequences, and upon which higher-order structures can be built. Folding of telomere DNA into G-quadruplexes appears to inhibit telomerase access. This activity is unlikely to be conserved in TPP1, as TPP1 lacks the basic domain of TEBP$\beta$ that is responsible for G-quadruplex-stimulating activity. In contrast, POT1 has been shown to inhibit G-quadruplex structure [89], suggesting evolutionary divergence in G-quadruplex control mechanisms. The core telomere proteins TIN2, TRF1 and TRF2 are not found in ciliates. These proteins seem to have evolved for telomere homeostasis in vertebrates, and may provide additional mechanisms for regulating telomere G-quadruplex formation.
Both TPP1 and POT1 are critical for regulating telomere length, and POT1 is the only telomere protein identified so far that binds to telomere ssDNA. TPP1 has been shown to be able to interact with telomerase both in vitro and in cells $[66,67]$ and its putative OB fold is required for telomerase recruitment. In addition to direct binding, the POT1-TPP1 complex appears to enhance the processivity of the telomerase component TERT in vitro [67]. Consistent with this finding, expressing a TPP1 mutant lacking the OB fold resulted in modest telomere shortening in human cells compared to parental cells or cells expressing full-length TPP1 [66]. Because TPP1 on its own does not bind ssDNA, this probably means that POT1 and TPP1 function together to recruit telomerase to telomeric ssDNA through the TPP1 OB fold, in addition to protecting telomere ends and negatively regulating telomerase access. Generally, telomeres only become accessible to the telomerase during the $\mathrm{S}$ phase of the cell cycle. This is achieved through multiple mechanisms, including regulation of telomerase expression and activity, sequestering of telomeres, and coating of telomeres with telomere-binding proteins such as POT1, which presumably serves to block telomerase access.

The realization that there are two classes of OB-foldcontaining proteins with distinct functions has in turn helped to establish a unified model regarding the function of OB-fold-containing proteins in telomere overhang binding (Table 1) [66-70]. While much conservation exists between the various OB-fold-containing complexes, differences such as DNA-binding specificities, domain structures, and interaction partners help to set these proteins apart. From yeast to human, RPA-like or TEBP heteromultimeric complexes may have evolved for the more specialized function of ssDNA protection at the telomeres [66,67,71-77].

\section{Compartmentalization of telomeric protein complexes}

Structural, temporal and developmental variation greatly impact on the assembly and disassembly of the various subcomplexes that make up the dynamic telomere interactome. While numerous studies have been carried out to elucidate protein-protein interactions and telomere localizations of multiple factors within the interactome (for example, TRF1, TIN2 and TRF2), surprisingly little is known regarding the subcellular localization and regulated targeting of core telomere proteins.

Proteins of the telosome have been found in cellular locations other than the telomeres. For example, TRF2 and RAP1 have been shown to associate with the Epstein-Barr virus origin of replication [90], and TRF2 can be recruited to intra-satellite double-strand breaks when the damage level is high [91]. The growth status of human cells may influence the localization of TIN2 [92]. In growth-arrested epithelial cells, TIN2 was found to migrate into non-telomeric domains that contained the protein $\mathrm{HP} 1$, a marker of heterochromatin. It is possible that different complexes may form under these different conditions. 
Table I

Evolution of telomere-end-binding proteins containing the $O B$ fold

\begin{tabular}{lll}
\hline Species & OB-fold proteins & Structure \\
\hline Budding yeast & CDCI3-Stn I-Ten I, Est3 & RPA-like \\
Fission yeast & POTI-TPPI & TEBP $\alpha / \beta$-like \\
Ciliate & TEBP $\alpha$-TEBP $\beta$ & TEBP $\alpha / \beta$ heterodimer \\
Vertebrates (frogs to humans) & POTI-TPPI & TEBP $\alpha / \beta$-like \\
\hline
\end{tabular}

Recent studies have indicated for the first time the importance of nuclear export and spatial control of telomeric proteins in telomere maintenance in mammalian cells, as endogenous TIN2, TPP1 and POT1 have been found to localize in both the cytoplasm and the nucleus [93]. In addition, as determined by bimolecular fluorescence complementation assays [93,94], different pairs of telomeric proteins appear to interact with each other in different cellular compartments. Whereas TIN2-TRF2 interaction takes place exclusively in the nucleus (including at telomeres), TIN2-TPP1 and TPP1-POT1 interactions occur in both the cytoplasm and nucleus. These results suggested telomere protein subcomplex formation in the cytoplasm. Interestingly, a nuclear export signal (NES) has been identified on TPP1 that directly controls the amount of TPP1 and POT 1 in the nucleus. This NES resides next to the POT1recruitment domain on $\mathrm{TPP} 1$, raising the possibility that interaction and nuclear localization of the TPP1-POT1 complex may be linked.

Binding of TIN2 to TPP1 promotes nuclear localization of TPP1 and POT1, by a mechanism yet to be determined [93]. The finding that TIN2 promotes nuclear retention of TPP1 and POT1 suggests that TIN2 plays a dual role in telosome assembly. While acting as a molecular tether for telosome subunits, TIN2 also ensures nuclear targeting and assembly of the entire complex. It would be of great interest to determine whether there exist other signaling pathways that control the nuclear import and export of telomeric complexes. Unexpectedly, disrupting TPP1 nuclear export can result in telomeric DNA damage response and telomere length disregulation [93]. This underlines the importance of spatial control of telomeric complexes, such that too much TPP1 in the nucleus may be detrimental to cells, and TPP1 nuclear export may regulate the concentration of TPP1-POT1 in the nucleus. These findings suggest that coordinated interactions among TIN2, TPP1 and POT1 in the cytoplasm could regulate the assembly and function of the telosome in the nucleus.

\section{Acknowledgements}

This work is supported by NIH grants CA84208 and GM69572 and the Welch Foundation. DL is supported in part by the American Heart Association. ZS is a Leukemia and Lymphoma Society Scholar.

\section{References}

I. Liu D, O'Connor MS, Qin J, Songyang Z: Telosome, a mammalian telomere-associated complex formed by multiple telomeric proteins. J Biol Chem 2004, 279:5 I338-5। 342

2. de Lange T: Shelterin: the protein complex that shapes and safeguards human telomeres. Genes Dev 2005, 19:2100-2110.

3. Broccoli D, Smogorzewska A, Chong L, de Lange T: Human telomeres contain two distinct Myb-related proteins, TRFI and TRF2. Nat Genet 1997, 17:231-235.

4. Bilaud T, Brun C, Ancelin K, Koering CE, Laroche T, Gilson E: Telomeric localization of TRF2, a novel human telobox protein. Nat Genet 1997, 17:236-239.

5. Shen M, Haggblom C, Vogt M, Hunter T, Lu KP: Characterization and cell cycle regulation of the related human telomeric proteins Pin2 and TRFI suggest a role in mitosis. Proc Natl Acad Sci USA 1997, 94:13618-13623.

6. Li B, Oestreich S, de Lange T: Identification of human Rap I: implications for telomere evolution. Cell 2000, I01:47I-483.

7. Baumann P, Cech TR: Potl, the putative telomere end-binding protein in fission yeast and humans. Science 200 I, 292: I I7I-I I 75.

8. Houghtaling BR, Cuttonaro L, Chang W, Smith S: A Dynamic Molecular Link between the Telomere Length Regulator TRFI and the Chromosome End Protector TRF2. Curr Biol 2004, | 14: 162 I- |63|.

9. Ye JZ, Hockemeyer D, Krutchinsky AN, Loayza D, Hooper SM, Chait BT, de Lange T: POTI-interacting protein PIPI: a telomere length regulator that recruits POTI to the TIN2/TRFI complex. Genes Dev 2004, 18:1649-1654.

10. Liu D, Safari A, O'Connor MS, Chan DW, Laegeler A, Qin J, Songyang Z: PTOP interacts with POTI and regulates its localization to telomeres. Nat Cell Biol 2004, 6:673-680.

II. Songyang Z, Liu D: Inside the mammalian telomere interactome: regulation and regulatory activities of telomeres. Crit Rev Eukaryot Gene Expr 2006, 16:103-118.

12. Fairall L, Chapman L, Moss H, de Lange T, Rhodes D: Structure of the TRFH dimerization domain of the human telomeric proteins TRFI and TRF2. Mol Cell 200I, 8:35I-36I.

13. Chen Y, Yang Y, van Overbeek M, Donigian JR, Baciu P, de Lange T, Lei M: A Shared Docking Motif in TRFI and TRF2 Used for Differential Recruitment of Telomeric Proteins. Science 2008, 319:10921096.

14. Stansel RM, de Lange T, Griffith JD: T-loop assembly in vitro involves binding of TRF2 near the 3' telomeric overhang. EMBO J 200I, 20:5532-5540.

15. Griffith JD, Comeau L, Rosenfield S, Stansel RM, Bianchi A, Moss H, de Lange T: Mammalian telomeres end in a large duplex loop. Cell 1999, 97:503-514.

16. Fouche N, Cesare AJ, Willcox S, Ozgur S, Compton SA, Griffith JD: The basic domain of TRF2 directs binding to DNA junctions irrespective of the presence of TTAGGG repeats. J Biol Chem 2006, 28I:37486-37495

17. Amiard S, Doudeau M, Pinte S, Poulet A, Lenain C, FaivreMoskalenko C, Angelov D, Hug N, Vindigni A, Bouvet P, Paoletti J, Gilson E, Giraud-Panis MJ: A topological mechanism for TRF2enhanced strand invasion.. Nat Struct Mol Biol 2007, 14:147-154.

18. Wang RC, Smogorzewska A, de Lange T: Homologous recombination generates T-loop-sized deletions at human telomeres. Cell 2004, II 9:355-368.

19. Karlseder J, Broccoli D, Dai Y, Hardy S, de Lange T: p53- and ATMdependent apoptosis induced by telomeres lacking TRF2. Science 1999, 283:1321-1325. 
20. van Steensel B, Smogorzewska A, de Lange T: TRF2 protects human telomeres from end-to-end fusions. Cell I998, 92:40 I-4I3.

21. Blackburn EH: Switching and signaling at the telomere. Cell 200I, 106:66I-673.

22. Wright WE, Shay JW: Cellular senescence as a tumor-protection mechanism: the essential role of counting. Curr Opin Genet Dev 2001, II:98-103.

23. Maser RS, DePinho RA: Connecting chromosomes, crisis, and cancer. Science 2002, 297:565-569.

24. Kim SH, Kaminker P, Campisi J: Telomeres, aging and cancer: in search of a happy ending.. Oncogene 2002, 21:503-5I I.

25. Baumann P: Are mouse telomeres going to pot? Cell 2006, 126:3336.

26. Blasco MA: The epigenetic regulation of mammalian telomeres. Nat Rev Genet 2007, 8:299-309.

27. Verdun RE, Karlseder J: Replication and protection of telomeres. Nature 2007, 447:924-931.

28. Longhese MP: DNA damage response at functional and dysfunctional telomeres. Genes Dev 2008, 22: I 25-140.

29. van Steensel B, de Lange T: Control of telomere length by the human telomeric protein TRFI. Nature 1997, 385:740-743.

30. Kim SH, Kaminker P, Campisi J: TIN2, a new regulator of telomere length in human cells. Nat Genet 1999, 23:405-412.

31 . Smith S, de Lange T: Tankyrase promotes telomere elongation in human cells. Curr Biol 2000, I0:1299-1302

32. Smogorzewska A, van Steensel B, Bianchi A, Oelmann S, Schaefer MR, Schnapp G, de Lange T: Control of human telomere length by TRFI and TRF2. Mol Cell Biol 2000, 20:1659-1668.

33. Smith S, Giriat I, Schmitt A, de Lange T: Tankyrase, a poly(ADPribose) polymerase at human telomeres. Science 1998, 282:।484 1487.

34. Zhou XZ, Lu KP: The Pin2/TRFI-interacting protein PinXI is a potent telomerase inhibitor. Cell 200I, 107:347-359.

35. Cong YS, Wright WE, Shay JW: Human telomerase and its regulation. Microbiol Mol Biol Rev 2002, 66:407-425.

36. Loayza D, De Lange T: POTI as a terminal transducer of TRFI telomere length control. Nature 2003, 424: I0I3-1018.

37. Lillard-Wetherell K, Machwe A, Langland GT, Combs KA, Behbehan GK, Schonberg SA, German J, Turchi JJ, Orren DK, Groden J: Association and regulation of the BLM helicase by the telomere proteins TRFI and TRF2. Hum Mol Genet 2004, 13:1919-1932.

38. Kim SH, Beausejour C, Davalos AR, Kaminker P, Heo SJ, Campisi J: TIN2 mediates functions of TRF2 at human telomeres. J Biol Chem 2004, 279:43799-43804.

39. Ye JZ, Donigian JR, Van Overbeek M, Loayza D, Luo Y, Krutchinsky AN, Chait BT, De Lange T: TIN2 binds TRFI and TRF2 simultaneously and stabilizes the TRF2 complex on telomeres. J Biol Chem 2004, 279:47264-4727I.

40. Nakamura M, Zhou XZ, Kishi S, Lu KP: Involvement of the telomeric protein Pin2/TRFI in the regulation of the mitotic spindle. FEBS Lett 2002, 514:193-198.

41. Zhu Q, Yasumoto H, Tsai RY: Nucleostemin Delays Cellular Senescence and Negatively Regulates TRFI Protein Stability. Mol Cell Biol 2006, 26:9279-9290

42. Lee TH, Perrem K, Harper JW, Lu KP, Zhou XZ: The F-box protein FBX4 targets PIN2/TRFI for ubiquitin-mediated degradation and regulates telomere maintenance. J Biol Chem 2006, 281:759-768.

43. Chang $P$, Coughlin M, Mitchison T]: Tankyrase-I polymerization of poly(ADP-ribose) is required for spindle structure and function. Nat Cell Biol 2005, 7: I I33-I I 39

44. Dynek JN, Smith S: Resolution of sister telomere association is required for progression through mitosis. Science 2004, 304:97-I 00.

45. Chang W, Dynek JN, Smith S: TRFI is degraded by ubiquitin-mediated proteolysis after release from telomeres. Genes Dev 2003 17:1328-1333.

46. Potts $\mathrm{PR}, \mathrm{Yu} \mathrm{H}$ : The SMC5/6 complex maintains telomere length in ALT cancer cells through SUMOylation of telomere-binding proteins. Nat Struct Mol Biol 2007, 14:581-590.

47. Bryan TM, Englezou A, Dalla-Pozza L, Dunham MA, Reddel RR: Evidence for an alternative mechanism for maintaining telomere length in human tumors and tumor-derived cell lines. Nat Med 1997, 3: $|27|-\mid 274$

48. Kishi S, Zhou XZ, Ziv Y, Khoo C, Hill DE, Shiloh Y, Lu KP: Telomeric protein Pin2/TRFI as an important ATM target in response to double strand DNA breaks. J Biol Chem 200I, 276:29282-2929I.
49. Wu Y, Xiao S, Zhu XD: MREI I-RAD50-NBSI and ATM function as co-mediators of TRFI in telomere length control. Nat Struct Mol Biol 2007, 14:832-840.

50. Zhu XD, Niedernhofer L, Kuster B, Mann M, Hoeijmakers JH, de Lange T: ERCCI/XPF removes the 3' overhang from uncapped telomeres and represses formation of telomeric DNA-containing double minute chromosomes. Mol Cell 2003, 12:1489-1498.

5I. van Overbeek M, de Lange T: Apollo, an Artemis-related nuclease, interacts with TRF2 and protects human telomeres in S phase. Curr Biol 2006, 16:1295-1302.

52. Lenain C, Bauwens S, Amiard S, Brunori M, Giraud-Panis MJ, Gilson E: The Apollo 5' exonuclease functions together with TRF2 to protect telomeres from DNA repair. Curr Biol 2006, 16:1303-I310.

53. Zhu XD, Kuster B, Mann M, Petrini JH, de Lange T: Cell-cycle-regulated association of RAD50/MREII/NBSI with TRF2 and human telomeres. Nat Genet 2000, 25:347-352.

54. O'Connor MS, Safari A, Liu D, Qin J, Songyang Z: The human Rap I protein complex and modulation of telomere length. $J$ Biol Chem 2004, 279:28585-2859I

55. Opresko PL, von Kobbe C, Laine JP, Harrigan J, Hickson ID, Bohr VA: Telomere-binding protein TRF2 binds to and stimulates the Werner and Bloom syndrome helicases.. J Biol Chem 2002, 277: $4 I I I 0-41119$.

56. Song $K$, Jung D, Jung $Y$, Lee SG, Lee I: Interaction of human Ku70 with TRF2. FEBS Lett 2000, 48I:8I-85.

57. Dantzer F, Giraud-Panis MJ, Jaco I, Amé JC, Schultz I, Blasco M, Koering CE, Gilson E, Ménissier-de Murcia J, de Murcia G, Schreiber $\mathrm{V}$ : Functional interaction between poly(ADP-Ribose) polymerase 2 (PARP-2) and TRF2: PARP activity negatively regulates TRF2. Mol Cell Biol 2004, 24: I595-1607.

58. Gomez M, Wu J, Schreiber V, Dunlap J, Dantzer F, Wang Y, Liu Y: PARPI Is a TRF2-associated Poly(ADP-Ribose)Polymerase and Protects Eroded Telomeres. Mol Biol Cell 2006, I7:1686-1696

59. Verdun RE, Crabbe L, Haggblom C, Karlseder J: Functional human telomeres are recognized as DNA damage in $\mathrm{G} 2$ of the cell cycle.. Mol Cell 2005, 20:55I-56I.

60. Verdun RE, Karlseder J: The DNA damage machinery and homologous recombination pathway act consecutively to protect human telomeres. Cell 2006, 127:709-720.

61. Bradshaw PS, Stavropoulos DJ, Meyn MS: Human telomeric protein TRF2 associates with genomic double-strand breaks as an early response to DNA damage.. Nat Genet 2005, 37:193-197.

62. Williams ES, Stap J, Essers J, Ponnaiya B, Luijsterburg MS, Krawczyk PM, Ullrich RL, Aten JA, Bailey SM: DNA double-strand breaks are not sufficient to initiate recruitment of TRF2. Nat Genet 2007, 39:696-698; author reply 698-699.

63. Li B, de Lange T: Rapl affects the length and heterogeneity of human telomeres. Mol Biol Cell 2003, 14:5060-5068.

64. Atanasiu C, Deng Z, Wiedmer A, Norseen J, Lieberman PM: ORC binding to TRF2 stimulates OriP replication. EMBO Rep 2006, 7:7I6721

65. O'Connor MS, Safari A, Xin H, Liu D, Songyang Z: A critical role for TPPI and TIN2 interaction in high-order telomeric complex assembly. Proc Natl Acad Sci USA 2006, 103: I I 874- I I 879.

66. Xin H, Liu D, Wan M, Safari A, Kim H, Sun W, O'Connor M S, Songyang Z: TPPI is a homologue of ciliate TEBP-beta and interacts with POTI to recruit telomerase.. Nature 2007, 445:559-562.

67. Wang F, Podell ER, Zaug AJ, Yang Y, Baciu P, Cech TR, Lei M: The POTI-TPPI telomere complex is a telomerase processivity factor. Nature 2007, 445:506-5I0.

68. Horvath MP, Schweiker VL, Bevilacqua JM, Ruggles JA, Schultz SC: Crystal structure of the Oxytricha nova telomere end binding protein complexed with single strand DNA.. Cell I 998, 95:963-974.

69. Lei M, Podell ER, Baumann P, Cech TR: DNA self-recognition in the structure of Potl bound to telomeric single-stranded DNA.. Nature 2003, 426:198-203.

70. Lei M, Podell ER, Cech TR: Structure of human POTI bound to telomeric single-stranded DNA provides a model for chromosome end-protection. Nat Struct Mol Biol 2004, II:I223-I 229.

7I. Martin V, Du LL, Rozenzhak S, Russell P: Protection of telomeres by a conserved Stnl-Tenl complex. Proc Natl Acad Sci USA 2007 104:|4038-|4043.

72. Gao H, Cervantes RB, Mandell EK, Otero JH, Lundblad V: RPA-like proteins mediate yeast telomere function. Nat Struct Mol Biol 2007 |4:208-2|4 
73. Bochkarev A, Bochkareva E: From RPA to BRCA2: lessons from single-stranded DNA binding by the OB-fold. Curr Opin Struct Bio 2004, 14:36-42.

74. Iftode C, Daniely Y, Borowiec JA: Replication protein A (RPA): the eukaryotic SSB. Crit Rev Biochem Mol Biol 1999, 34: I4 I-I80.

75. Miyoshi T, Kanoh J, Saito M, Ishikawa F: Fission yeast Potl-Tppl protects telomeres and regulates telomere length. Science 2008, 320:1341-1344.

76. Lee J, Mandell EK, Tucey TM, Morris DK, Lundblad V: The Est3 protein associates with yeast telomerase through an $\mathrm{OB}$-fold domain. Nat Struct Mol Biol 2008, I5: 990-997.

77. Young Yu E, Wang F, Lei M, Lue NF: A proposed OB-fold with a protein-interaction surface in Candida albicans telomerase protein Est3. Nat Struct Mol Biol 2008, 15:985-989.

78. Shakirov EV, Surovtseva YV, Osbun N, Shippen DE: The Arabidopsis Pot I and Pot2 proteins function in telomere length homeostasis and chromosome end protection. Mol Cell Biol 2005, 25:7725-7733.

79. Hockemeyer D, Daniels JP, Takai H, de Lange T: Recent expansion of the telomeric complex in rodents: Two distinct POTI proteins protect mouse telomeres. Cell 2006, 126:63-77.

80. Wu L, Multani AS, He H, Cosme-Blanco W, Deng Y, Deng JM, Bachilo O, Pathak S, Tahara H, Bailey SM, Deng Y, Behringer RR, Chang S: Potl deficiency initiates DNA damage checkpoint activation and aberrant homologous recombination at telomeres. Cell 2006, 126:49-62

81. Churikov D, Wei C, Price CM: Vertebrate POTI restricts G-overhang length and prevents activation of a telomeric DNA damage checkpoint but is dispensable for overhang protection. Mol Cell Biol 2006, 26:697I-6982.

82. Jacob NK, Lescasse R, Linger BR, Price CM: Tetrahymena POTIa regulates telomere length and prevents activation of a cell cycle checkpoint. Mol Cell Biol 2007, 27:I592-I60I.

83. He H, Multani AS, Cosme-Blanco W, Tahara H, Ma J, Pathak S, Deng Y, Chang S: POTIb protects telomeres from end-to-end chromosomal fusions and aberrant homologous recombination. EMBO J 2006, 25:5180-5190.

84. Denchi EL, de Lange T: Protection of telomeres through independent control of ATM and ATR by TRF2 and POTI. Nature 2007, 448: $1068-1071$.

85. Guo X, Deng Y, Lin Y, Cosme-Blanco W, Chan S, He H, Yuan G, Brown EJ, Chang S: Dysfunctional telomeres activate an ATM-ATRdependent DNA damage response to suppress tumorigenesis. EMBO J 2007, 26:4709-47I9.

86. Zhou BB, Elledge SJ: The DNA damage response: putting checkpoints in perspective. Nature 2000, 408:433-439.

87. Zou L, Elledge SJ: Sensing DNA damage through ATRIP recognition of RPA-ssDNA complexes. Science 2003, 300:1542-I 548.

88. Fang G, Cech TR: The beta subunit of Oxytricha telomere-binding protein promotes G-quartet formation by telomeric DNA. Cell 1993, 74:875-885

89. Zaug AJ, Podell ER, Cech TR: Human POTI disrupts telomeric Gquadruplexes allowing telomerase extension in vitro. Proc Natl Acad Sci USA 2005, 102:10864-10869.

90. Deng Z, Atanasiu C, Burg JS, Broccoli D, Lieberman PM: Telomere repeat binding factors TRFI, TRF2, and hRAPI modulate replication of Epstein-Barr virus OriP. J Virol 2003, 77: I I 992-I 2001.

91. Bradshaw PS, Stavropoulos DJ, Meyn MS: Human telomeric protein TRF2 associates with genomic double-strand breaks as an early response to DNA damage. Nat Genet 2005, 37:193-197.

92. Kaminker P, Plachot C, Kim SH, Chung P, Crippen D, Petersen OW, Bissell MJ, Campisi J, Lelievre SA: Higher-order nuclear organization in growth arrest of human mammary epithelial cells: a novel role for telomere-associated protein TIN2. J Cell Sci 2005, I I 8: I 32 I-I 330.

93. Chen LY, Liu D, Songyang Z: Telomere maintenance through spatial control of telomeric proteins. Mol Cell Biol 2007, 27:5898-5909.

94. Hu CD, Kerppola TK: Simultaneous visualization of multiple protein interactions in living cells using multicolor fluorescence complementation analysis. Nat Biotechnol 2003, 21:539-545. 